\title{
A SUCCESSFUL PREGNANCY OUTCOME IN UNICORNUATE UTERUS
}

\author{
B. Kalpana ${ }^{1}$, Richa Gupta ${ }^{2}$
}

${ }^{1}$ Consultant and HOD, Department of Reproductive Medicine, Guru Hospital, Madurai.

2Junior Consultant, Department of Reproductive Medicine, Guru Hospital, Madurai.

HOW TO CITE THIS ARTICLE: Kalpana B, Gupta R. A successful pregnancy outcome in unicornuate uterus. J. Evolution Med. Dent. Sci. 2017;6(73):5276-5277, DOI: 10.14260/Jemds/2017/1145

\section{PRESENTATION OF CASE}

A 42 years old woman, married since 11 years came to us as a case of primary infertility, desirous of conception. She has attained menopause 1 year back. Her previous menstrual cycles were regular with no dysmenorrhoea. Basic USG was done which showed a bulky, anteverted uterus with endometrial thickness of $3 \mathrm{~mm}$. B/L ovaries were small and both kidneys were normal. It was followed by an MRI, which showed an $\mathrm{A} / \mathrm{V}$ stretched uterus with fundus adherent to anterior abdominal wall and bilateral small ovaries. Bilateral kidneys were normal.

Hysterolaparoscopy was planned. Hysteroscopy revealed a cervix flushed with vault. Left ostium was not seen suggestive of right unicornuate uterus. Laparoscopy revealed uterus adherent to anterior abdominal wall. Fundus was buried in omental adhesions, which were released. Right tube and ovary were seen. Diagnosis of right unicornuate uterus was made. Left horn was rudimentary and noncommunicating, hence we decided not to remove it.

Patient conceived after 2 - 3 months with IVF (ICSI) treatment. First scan showed 9 wks triplet pregnancy with early demise of $3^{\text {rd }}$ foetus. She underwent Multifoetal Pregnancy Reduction (MFPR) from twins to singleton pregnancy. Cervical encerclage was done. A detailed Level II anomaly scan was done revealing no gross anomalies in the baby. Patient was given progesterone support during pregnancy. Injection Betamethasone was administered at 33 weeks. Patient had regular antenatal check-ups and pregnancy was followed up with serial ultrasounds till term.

LSCS was performed at 37 weeks 4 days I/V/O IVF Conception with Uterine anomaly with Breech presentation in labour and a healthy $2.4 \mathrm{~kg}$ female baby was born by Breech extraction. Baby was vigorous at birth and cried immediately. OT findings revealed a Unicornuate uterus with welldeveloped right horn and a non-communicating rudimentary left horn. Both tubes and ovaries were normal. Foley's was draining clear urine at the end of the procedure.

Post-operative course was uneventful. Patient was discharged on $14^{\text {th }}$ post-op day.

Financial or Other, Competing Interest: None.

Submission 02-08-2017, Peer Review 27-08-2017,

Acceptance 01-09-2017, Published 11-09-2017.

Corresponding Author:

Dr. B. Kalpana,

$\# 4 / 120 \mathrm{~F}$,

Pandikovil Ring Road,

Madurai- 625107, Tamilnadu.

E-mail: balamurugan_kalpana@rediffmail.com

DOI: $10.14260 /$ jemds/2017/1145

\section{(c) $($ ) $(\$)$}

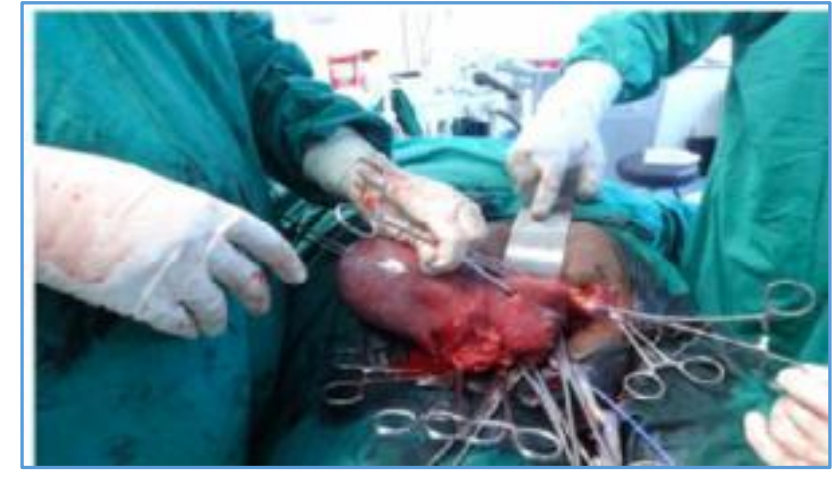

Image 1. Right Unicornuate Uterus with Left Rudimentary Horn at LSCS

\section{DIFFERENTIAL DIAGNOSIS}

Unicornuate uterus with or without horn with or without cavity.

\section{CLINICAL DIAGNOSIS}

Right unicornuate uterus with rudimentary left horn.

\section{PATHOLOGICAL DISCUSSION}

Congenital uterine anomalies are present in 1 to $10 \%$ of the unselected population, 2 to $8 \%$ of infertile women and 5 to $30 \%$ of women with history of miscarriages.[1] A unicornuate uterus is a type II classification with unilateral hypoplasia or agenesis that can be further sub-classified into communicating or non-communicating cavity and horn. ${ }^{[2]}$ A rudimentary horn with unicornuate uterus results from failure of complete development of one of the Müllerian ducts associated with the incomplete fusion of the contralateral one. The presence of a uterine anomaly is associated with an increased risk of preterm birth, preterm premature rupture of membranes, breech presentation, caesarean section, placenta previa, placental abruption and intrauterine growth retardation (IUGR). ${ }^{[3]}$ A unicornuate uterus is present in $0.1 \%$ of the unselected population. The reproductive performance of women with unicornuate uterus is poor with a live birth rate of only $29.2 \%$, prematurity rate of $44 \%$ and an ectopic pregnancy rate of $4 \% .{ }^{[4]}$ Moreover, women with this anomaly have $24.3 \%$ chances of first trimester abortion, $9.7 \%$ second trimester abortion and $10.5 \%$ intrauterine foetal demise. ${ }^{[5]}$ It has been suggested that first trimester abortion, intrauterine growth restriction and stillbirths may be explained by an abnormal uterine blood flow (absent or abnormal uterine or ovarian artery). Second trimester abortions and preterm deliveries are thought to be due to decreased muscle mass in the unicornuate uterus as well as cervical incompetence. 
Unicornuate uterus with non-communicating rudimentary horn is susceptible to many gynaecological and obstetric complications, which can occur at any stage of reproductive life. It is difficult to truly estimate the incidence of these complications. If in patients presenting with infertility, hysterosalpingography shows that the uterus is deviated to one side and there is unilateral tubal block. This condition should be strongly suspected. Endometriosis is another complication that is seen in these patients. In one study, the incidence was as high as $20 \% .^{5}$ Pregnancy in a rudimentary horn is very rare, but it can be life threatening. Even though Nanda et al[6] described a successful twin pregnancy in a unicornuate uterus with one foetus in the non-communicating rudimentary horn, many other cases of ruptured noncommunicating rudimentary horn pregnancies have been described. $[7,8]$

A unicornuate uterus with rudimentary horn is often associated with ectopic pregnancies and with rupture of the rudimentary horn and although it is unclear whether or not to remove the rudimentary horn before conception or early in pregnancy. As it is associated with such catastrophe every effort should be made to diagnose it in early pregnancy, but according to the literature less than $5 \%$ of the reported cases were diagnosed preoperatively and mostly the diagnosis was made at laparotomy or laparoscopy.[9]

Ultrasonography can also pick up this anomaly with reasonable accuracy. MRI and CT scan are also gaining popularity for diagnosing uterine malformations.

When the pregnancy is located in the semi-uterus of the anomaly it is associated with high incidence of abortion, preterm labour, cervical incompetence, malpresentation, IUGR and caesarean section rate and these obstetrical risks can be reduced but not completely eliminated by a particular pregnancy followup and specific interventions.

According to the current guidelines of the American Congress of Obstetricians and Gynaecologists (ACOG) for the management of IUGR,[10] it is reasonable to consider serial growth ultrasound examinations in pregnancies at risk of IUGR as in the case of a unicornuate uterus pregnancy.

As for the risk of preterm labour, there are no consistent data that any intervention can delay delivery in women for longer than 24 to 48 hours once they present a preterm labour. For this reason, much attention has been focused on preventive strategies rather than on intervention strategies. Although, several strategies have been proposed, the prevention of preterm birth has been largely unsuccessful.[11]

The utility of ultrasound cervix length measurement for assessing the risk of preterm birth has been well documented with an accepted cut-off value for cervix length of $\leq 25 \mathrm{~mm}$ before the 24 th week of gestational age. The predictive value of a negative test is high (92\%). This implies that pregnant women who do not have a shortened cervix can be reassured and unnecessary therapeutic measures can be avoided. By contrast cervical encerclage is the best treatment for women with a short cervix $(<25 \mathrm{~mm})$ and particularly for women with a history of prior mid-trimester pregnancy losses due to cervical insufficiency. Therefore, in our case report, a cervical encerclage was considered necessary.
In all such cases, evaluation of renal system is indicated because of the high incidence of associated urological anomalies. In our case, no associated urogenital anomalies were detected.

\section{CONCLUSION}

Our case report shows that by adopting these strategies the prognosis of pregnancy in a unicornuate uterus is not always impaired, although Breech presentation, caesarean delivery and prematurity threatens to occur.

Nevertheless, the optimal management approach cannot be clearly stated. Further large observational and prospective studies are essential to investigate the treatments needed during pregnancies in this uterine anomaly.

\section{FINAL DIAGNOSIS}

Successful pregnancy outcome in right unicornuate uterus with rudimentary and non-communicating left horn.

\section{REFERENCES}

[1] Chan YY, Jayaprakasan K, Tan A, et al. Reproductive outcomes in women with congenital uterine anomalies: a systematic review. Ultrasound Obstet Gynecol 2011;38(4):371-82.

[2] Grimbizis GF, Campo R. Clinical approach for the classification of congenital uterine malformations. Gynecol Surg 2012;9(2):119-29.

[3] Hua M, Odibo AO, Longman RE, et al. Congenital uterine anomalies and adverse pregnancy outcomes. Am J Obstet Gynecol 2011;205(6):558. e1-5.

[4] Akar ME, Bayar D, Yildiz S, et al. Reproductive outcome of women with unicornuate uterus. Aust N Z J Obstet Gynaecol 2005;45(2):148-50.

[5] Reichman D, Laufer MR, Robinson BK. Pregnancy outcomes in unicornuate uteri: a review. Fertil Steril 2009;91(5):1886-94.

[6] Nanda S, Dahiya K, Sharma N, et al. Successful twin pregnancy in a unicornuate uterus with one fetus in the non-communicating rudimentary horn. Arch Gynecol Obstet 2009;280(6):993-5.

[7] Amritha B, Sumangali T, Priya B, et al. A rare case of term viable secondary abdominal pregnancy following rupture of a rudimentary horn: a case report. J Med Case Rep 2009;3:38.

[8] Kanagal DV, Hanumanalu LC. Ruptured rudimentary horn pregnancy at 25 weeks with previous vaginal delivery: a case report. Case Rep Obstet Gynecol 2012;2012:4

[9] O'Leary JL, O'Leary JA. Rudimentary horn pregnancy. Obstet Gynecol 1963;22:371-5.

[10] American Congress of Obstetrics and Gynecology Committee on Practice Bulletins-Obstetrics: ACOG practice bulletin: intrauterine growth restriction. Obstet Gynecol 2000;95(Suppl):1-12.

[11] Norwitz ER, Caughey AB. Progesterone supplementation and the prevention of preterm birth. Rev Obstet Gynecol 2011;4(2):60-72. 